\title{
Plataforma para robótica educacional: integrando smartphone com programação em blocos.
}

\section{Samuel Cardoso Zampolli Fraga*, João Vilhete Viegas d'Abreu}

\section{Resumo}

Este projeto visa o desenvolvimento de uma plataforma de robótica educacional que abrange um dispositivo de controle robótico (módulo robótico), um software de programação em blocos para programar o referido dispositivo e um aplicativo de smartphone capaz de comandá-lo remotamente. O módulo robótico abarca uma placa de controle Arduino, uma de comunicação bluetooth, conectores externos e um circuito integrado para acionamento de motores. A partir do smartphone, utilizando o aplicativo, o usuário envia comandos para o módulo robótico pressionando botões na tela ou movimentando o aparelho (o movimento é monitorado pelo sensor acelerômetro). A programação do módulo robótico é elaborada em liguagem de blocos, através de um software livre que foi adaptado para o uso dos recursos de controle remoto. O projeto está sendo desenvolvido no Núcleo de Informática Aplicada à Educação (NIED - UNICAMP), com fomento do CNPq através do programa PIBIC.

\section{Palavras-chave:}

Robótica educacional, smartphone, programação em blocos.

\section{Introdução}

Ao longo de sua evolução, a Robótica Educacional apresentou importantes contribuições para o desenvolvimento de habilidades e competências dos alunos nos ambientes de ensino e aprendizagem. Apesar disso, o uso pedagógico da robótica ainda é bastante reduzido no Brasil e paulatinamente têm-se dado uma atenção maior à sua implementação nas escolas da rede pública. Neste cenário, o presente projeto trata do desenvolvimento de uma plataforma de robótica educacional que une um dispositivo robótico de aplicação versátil (módulo robótico), a linguagem de blocos para o ensino de programação e o uso do smartphone como um recurso para estimular o envolvimento dos alunos.

\section{Resultados e Discussão}

O dispositivo robótico foi construído incorporando num único módulo uma placa de controle Arduino, uma placa bluetooth que realiza a comunicação do dispositivo com o smartphone e um circuito integrado para controle de motores de corrente contínua tipicamente usados em projetos de robótica. Também foram incluídas no módulo entradas USB destinadas à conexão com sensores e atuadores externos (digitais ou analógicos), e um circuito para alimentação desses sensores e atuadores. A Figura 1 mostra um diagrama de blocos do módulo robótico, indicando o fluxo de informação entre seus componentes.

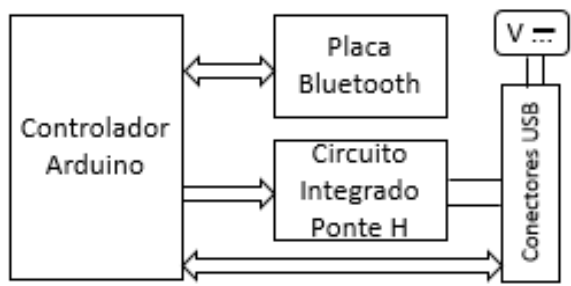

Figura 1. Diagrama de blocos do módulo robótico.

Para enviar comandos ao módulo robótico pelo smartphone, foi desenvolvido um aplicativo para sistema Android com uma interface de controle que possui botões e apresenta os dados do acelerômetro do celular (sensor que detecta a posição relativa do aparelho).

Dessa forma, o módulo robótico pode ser programado para requisitar informações do aplicativo via bluetooth, e então executar alguma atividade dependendo do estado de um botão (se está pressionado ou não) ou dos valores medidos pelo acelerômetro.

A programação do módulo robótico é feita no ambiente Mixly ${ }^{1}$, um software de programação em blocos com código aberto no qual foram feitas algumas adequações a fim de possibilitar sua interação com a plataforma. $\mathrm{O}$ software recebeu um conjunto de blocos que habilitam o uso dos recursos do aplicativo e permitem acionar dois motores através da ponte $\mathrm{H}$. Os blocos criados (Figura 2) se encaixam a outros blocos nativos do Mixly para formar o algoritmo a ser executado pelo robô.

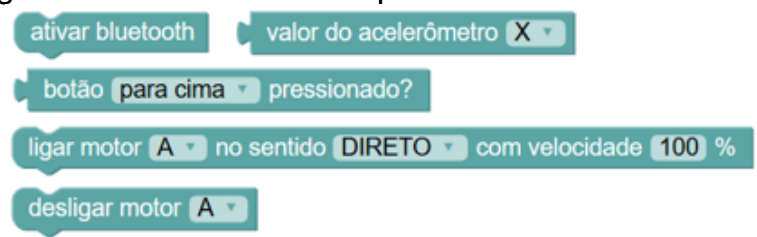

Figura 2. Blocos de programação.

\section{Conclusões}

As ferramentas de software desenvolvidas já demonstraram usabilidade ao serem aplicadas em projetos dos programas PIBIC-EM e Ciência e Arte nas Férias realizados no NIED por alunos do ensino médio durante o primeiro semestre de 2019. Aliado a isso, o módulo robótico permite a construção de uma grande variedade de robôs e protótipos de sistemas automatizados, contando com conexão facilitada a sensores e atuadores. Pretendemos estudar sua utilização em escolas públicas de nível fundamental e médio, elaborando e executando atividades envolvendo alunos e professores.

\section{Agradecimentos}

Ao CNPq e PRP, órgãos de fomento do projeto através do programa PIBIC; ao Núcleo de Informática Aplicada à Educação (NIED), local de desenvolvimento do projeto.

\footnotetext{
1 Website Arduino. Disponível em: <https://www.arduino.cc/>. Acesso em janeiro de 2019

2 Código de desenvolvimento do Mixly. Disponível em: <https://github.com/xbed/Mixly_Arduino>. Acesso em janeiro de 2019.
} 